\title{
RESEARCH THE POSSIBILITY OF OBTAINING DIAGNOSTIC INFORMATION ABOUT THE SHIPS ENGINE FUEL INJECTION SYSTEM CONDITION BASED ON THE ANALYSIS OF CHARACTERISTICS OF HEAT RELEASE
}

\author{
Kazimierz Witkowski \\ Gdynia Maritime University, Faculty of Marine Engineering \\ Morska Street 83, 81-225 Gdynia \\ tel.: +48585586332 \\ e-mail:k.witkowski@wm.umg.edu.pl
}

\begin{abstract}
Marine engines are very complex technical objects, having many important functional systems, which include, inter alia, injection system, characterized by high unreliability. In this system, there may be different types of defects (damage) that affect the engine parameters, including specific fuel consumption, as well as failures endanger the safety of the ship. The indicator diagrams and analysis of indicated parameters have limited utility in the diagnosis of damages of marine engine, although this is a method commonly used in operational practice. To achieve greater diagnostic effectiveness, when, based on indicator diagrams, are calculated and then the characteristics of heat release is analysed - net of heat release characteristics and the intensity of the heat release, it was demonstrated. This procedure is particularly effective in the diagnosis of damages of marine diesel engine injection system components. It has been shown that the characteristics of heat release contain information about the condition of the injection systems, which enable to diagnose their failures. This is shown on the example of a clogged nozzle holes (their carbonizations). The obtained results allowed selecting the diagnosis symptoms, useful in detecting these faults in the injection system, from the characteristics of heat release: net heat release $(Q)$ and intensity of heat release $(q)$. The object of the research was typical marine medium speed engine Sulzer A25/30.
\end{abstract}

Keywords: marine diesel engine, indicated parameters, indicator diagram, heat release characteristics, injection system, diagnostic

\section{Introduction}

Main propulsion of ships as well as marine power station in the vast majority is the piston internal combustion diesel engine turbocharged [12]. There is a direct relationship between reliability of engines for main propulsion and power station, and marine navigation safety and operating costs.

The operating costs of marine diesel engine are very high, primarily because of the relatively high prices of fuels and lubricating oils. Hence, the cost of exploiting them are even over $70 \%$ of the operating costs of the entire engine room and have a significant share in the costs of operation of the vessel. The increase of these costs may affect the current technical condition of the ship's engine. Decline in its efficiency will cause an increase in fuel consumption $[2,3,6,8]$.

Marine engines are very complex technical objects, having many important functional systems, which include, inter alia, injection system, characterized by high unreliability. In this system, there may be different types of defects (damage) that affect the engine parameters, including specific fuel consumption, as well as failures endanger the safety of the ship.

\section{Typical damage to the components of the injection system and their impact on the operation of the ship engine}

From the statistical data $[10,1]$ concerning the most common damage to the ships follows that, they relate to low-speed engines $-38.0 \%$ damage, medium speed engines $-15.7 \%$ and other 
damage to the concern of other machinery and marine equipment. Looking specifically on their failure has shown that the most unreliable engine fuel system (injection system). Statistics show that nearly $50 \%$ of all damage to marine engines is the fault of this system. In the injection system the most common damage occur in relation to the injectors $-41 \%$ and injection pumps $-38 \%$ and the fuel pipes $-12 \%$ (Fig. 1).

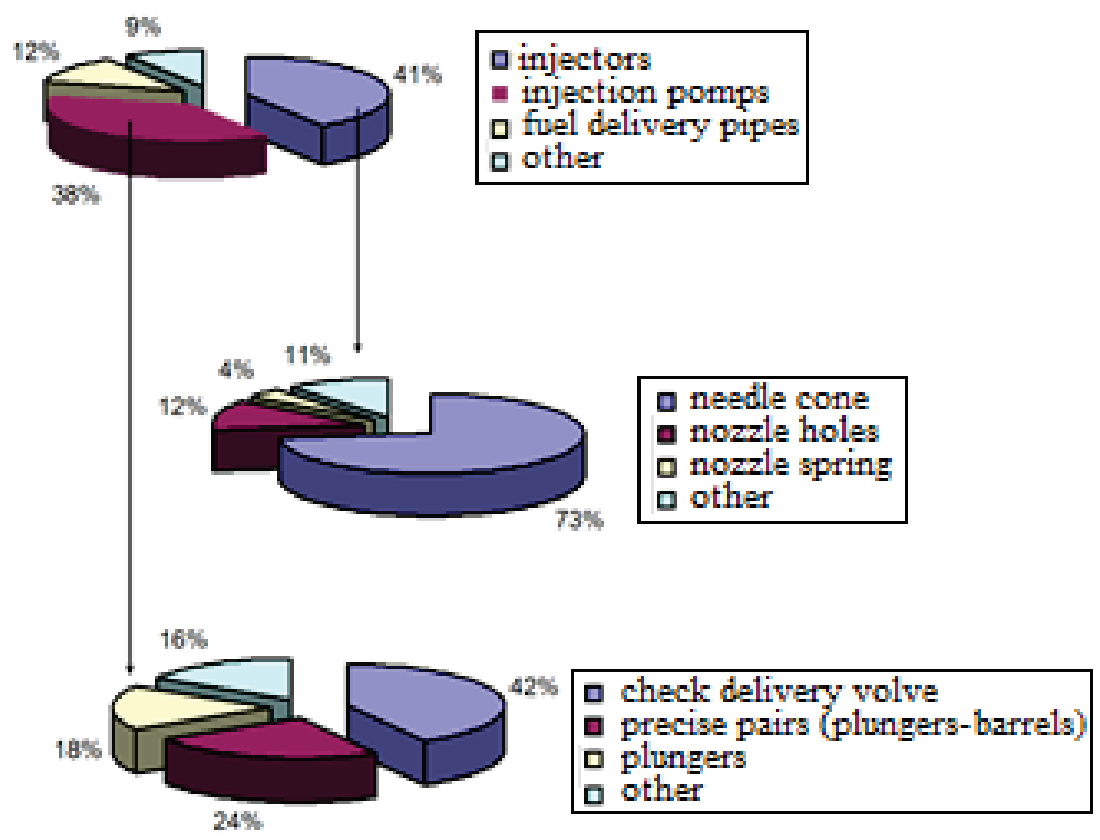

Fig. 1. Failure statistic of injection system components

Regarding to the damage caused by the most injectors is:

- wear cone of the needle $-73 \%$,

- wear hole and in the loss of patency nozzle holes injector $-12 \%$,

- loss of pressure spring stiffness (drop pressure opening injector) $-4 \%$,

- the other causes $-11 \%$

and damage to the injection pumps are associated with most often:

- leak delivery valves $-42 \%$,

- leak in pair of precise $-24 \%$,

- blurring of piston in injection pumps $-18 \%$,

- the other causes $-16 \%$.

The development of diagnostic methods is the basis for the ability to detect defects at an early stage of their formation, thus improving the operational safety by preventing failures.

The course and quality of combustion depend on the correct operation of the injection system and the supercharging system. Analysing causes of incorrect combustion is therefore advisable to identify the main factors affecting the working process. Above all those caused by irregularities in the operation of the injection system.

The symptoms allowing assessing the course of the combustion process are:

- Changes in exhaust gas temperature;

- Changes in the maximum combustion pressure;

- appearance (colour) of exhaust gases (smoking).

The increase in exhaust gas temperature can be caused by many factors, such as:

- non-optimal atomization of the injected fuel,

- too late injection of fuel,

- too late ignition,

- chronic combustion, 
also from outside the injection system, for example: overloading of the engine or cylinder, or insufficient scavenging of the cylinder.

The drop of exhaust gas temperature with unchanged fuel setting can be caused by such causes as:

- Fuel ignition is clearly too early;

- Periodic lack of ignition due to air-in of the injection system or the presence of water in the fuel;

- Clearly insufficient spraying of fuel.

The causes that affect for changes in exhaust gas temperature affect the maximum combustion pressure at the same time. Generally, it can be assumed that the increase in exhaust gas temperature is accompanied by a decrease in the maximum pressure, while the decrease in exhaust gas temperature causes increase in the maximum pressure.

The moment of injection has a significant influence on the value of the maximum combustion pressure, or more precisely - the associated with this moment of ignition. The early injection (ignition) triggers the increase of the maximum pressure, while the delay - the decrease of the maximum pressure. In the majority of large marine engines, a change in the fuel injection advance angle by $1^{\circ}$ results in a change in the maximum combustion pressure from 0.1 to $0.4 \mathrm{MPa}$.

The maximum combustion pressure $p_{\max }$ is a parameter influenced by all parameters of the work process components, in particular:

- the moment of injection and ignition of fuel (injection timing and fuel ignition angle expressed in relation to the top dead centre piston position - TDC),

- the size of the injected fuel dose as well,

- fuel quality and quality of the resulting fuel-air mixture.

Also:

- the pressure and temperature of the charging air,

- pressure and temperature at the end of the compression stroke.

For diagnostic purposes, an important information next to $p_{\max }$ is also the angle of occurrence of the maximum pressure relative to TDC $\left(\alpha_{p \max }\right)$. However, this data can only be obtained if the engine is equipped with an electronic indicator. An increase in $\alpha_{p \max }$ relative to the reference value, with a decrease in $p_{\max }$, may indicate delayed fuel injection or the use of a precise injection pump steam. On the other hand, the decrease in the $\alpha_{p \max }$ and the increase in $p_{\max }$ are mainly caused by the fuel injection too early.

Faulty operation of the injection system can cause engine smoke. The reasons for this are in fact the same phenomena that cause an increase in exhaust gas temperature - too late injection or ignition of the fuel and inadequate operation of the injector, but also insufficient fresh air charge in the cylinder (small amount of scavenge air) or overloading the entire engine, only one or several cylinders.

To sum up, it should be noted that damage to the injection system components, unfortunately often occurring in operation, have an impact on the engine operation, and so change in the injector opening pressure $\left(Z_{c o w}\right)$, wear of the spray holes $\left(Z_{o r}\right)$, wear an injection pump $\left(Z_{p p}\right)$ and clogging (carbonization) atomizer holes $\left(Z_{\text {otw.r }}\right)$, change the following parameters:

$$
\begin{gathered}
Z_{\text {cow }} \Rightarrow\left(T_{g} \uparrow, p_{\text {max }} \downarrow, p_{\text {max wtr. }} \downarrow\right) \Rightarrow\left(g_{e} \uparrow, \tau_{s} \uparrow\right), \\
Z_{o r} \Rightarrow\left(T_{g} \downarrow, p_{\text {max }} \uparrow, p_{\text {max wtr. }} \downarrow, u_{c} \downarrow\right) \Rightarrow\left(g_{e} \uparrow\right), \\
Z_{p p} \Rightarrow\left(\eta_{h} \downarrow, T_{g} \downarrow, p_{\max } \downarrow, p_{\text {max wtr. }} \downarrow, p_{i} \downarrow\right) \Rightarrow\left(g_{e} \uparrow, N_{i} \downarrow\right), \\
Z_{\text {otw. } r} \Rightarrow\left(p_{\text {max wtr. }} \uparrow, T_{g} \uparrow, p_{\max } \downarrow, p_{i} \downarrow\right) \Rightarrow\left(g_{e} \uparrow\right),
\end{gathered}
$$

where:

$T_{g} \quad$ - temperature exhaust outlet,

$p_{\max } \quad$ maximum combustion pressure,

$p_{\text {max wtr. }}-$ maximum injection pressure, 
$g_{e}$ - specific fuel consumption,

$u_{c}$ - the out flow rate of fuel from the injector,

$\tau_{c}$ - combustion time,

$p_{i}$ - mean indicated pressure,

$N_{i}$ - indicated power.

As it results from the above considerations, the result of the occurrence of the aforementioned damages in the injection system is a particularly noticeable change in such parameters as: maximum cylinder pressure $\left(p_{\max }\right)$, maximum fuel injection pressure $\left(p_{\max \cdot \mathrm{wtr}}\right)$ and gas temperature after the cylinder $\left(T_{g}\right)$. They also cause changes in the mean indicated pressure $\left(p_{i}\right)$, specific fuel consumption $\left(g_{e}\right)$ and combustion time $\left(\tau_{c}\right)$. In summary, it can be concluded that:

- the quality of regulation and the reliability of the operation of marine engine injection systems has a fundamental impact on the work process, and hence on the performance and trouble-free operation of the engine,

- statistical data on damage to marine engines indicate that about $50 \%$ of them concerning injection systems,

- in the injection system, the most unreliable elements are injectors $-41 \%$ damage and injection pumps $-38 \%$ damage,

- it is advisable to search for, develop and apply diagnostic methods that enable early detection of damage to injection system components under operating conditions.

\section{Possibilities of diagnosing damage in the injection system under operating conditions}

Functional system of marine engine, which has basic influence on the quality of the work process, the economics of operation of the engine and its reliability, is the injection system.

During running the marine engine, operational supervision the engine fuel supply system is reduced to operating current control operating parameters as well as for periodic cleaning of fuel filters and centrifuges as well as tightness control the entire system. The main parameters because of which engineer oversee, the work of the engine fuel supply system is: pressure and temperature (viscosity) of fuel.

Regarding to the injection system condition of the injectors is checked periodically. To evaluate the operation of the injection system are mainly used the following parameters:

a) operational (routinely measured):

- the exhaust gas temperature, $T_{g}$,

b) read with indicator diagrams:

- maximum combustion pressure, $p_{\max }$

- mean indicated pressure, $p_{i}$,

- the angle where $p_{\max }$ occurs, referred to TDC, $\alpha_{p \max }$.

In the diagnosis of defects in the injection system would be useful to measure the pressure in the system. The main parameters determined on the basis of this measurement are:

- the maximum injection pressure fuel injectors, $p_{\text {max.wtr, }}$

- injector opening pressure, $p_{\text {otw wtr, }}$

- the angle of injection period, $\alpha_{\mathrm{wtr}}$.

The parameters read on the basis of recorded pressure in injection system are indeed important diagnostic, but their measurement is difficult due to the limited sensors installation possibilities.

An example of a graph of pressure changes in the injection system is shown in Fig. 2.

Figure 3 shows an example of such graph obtained on SULZER four-stroke medium-speed engine type A25 / 30. This drawing compares the pressure waveforms for the reference state (without damage) and simulates the clogging atomizer holes. For this damage, the pressure in the injection pipe increased significantly at the end of the pressing. The maximum fuel injection pressure is about $10 \mathrm{MPa}$ higher than the reference value - without damage. 


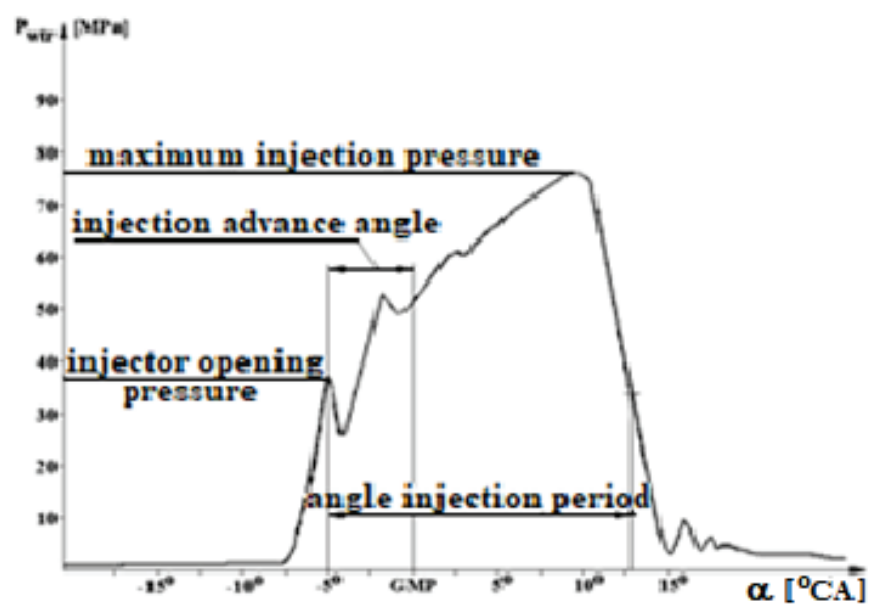

Fig. 2. An example diagram of pressure changes in the injection system and its characteristic values: maximum injection pressure $\left(p_{\max } w \mathrm{r} r\right)$, injector opening pressure $\left(p_{\text {otw.wtr }}\right)$, actual injection timing $(\alpha w w)$, injection advance angle $\left(\alpha_{w t r}\right), \alpha$-degrees crankshaft angle [ $\left.{ }^{\circ} \mathrm{CA}\right]$ [11]

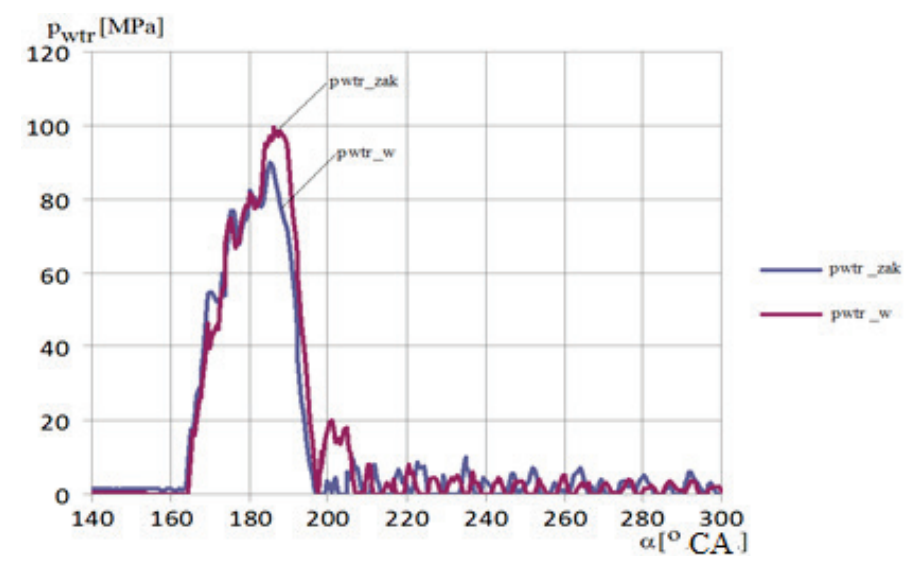

Fig. 3. Graphs of pressure change in the injection system for the engine load of $75 \%$ of nominal: pwtr_w-work without damage, pwtr_zak-work with clogged injection holes (two of the nine holes clogged)

Injection system, for security reasons, must be leak-proof. Injection piping commonly placed in special cases ("buffer zones"), which in the case of damage to the fuel pipe do not allow uncontrolled effluent of fuel to the engine room.

Therefore, it is advisable to search for such an effective method of diagnosing damages of the injection system, which does not require interference in the injection system. This condition corresponds to methods based on the analysis of the information contained in the indicator diagrams. This will be the indirect method to evaluation of the technical condition of injection equipment, which will cancel costly and unreliable measuring systems the pressure in the injection systems.

In order to obtain an effective method for the identification of major damages components in the injection system in-depth analysis of indicator diagrams is needed. This refers to the designation because of the indicator diagram heat release characteristics, obtained based on the measurement of cylinder pressure the electronic indicator. Cylinder pressure transducers mounted on the indicator valves.

\section{Assessment of the possibility of detecting the clogged of the injector holes based on heat release characteristics}

This part presents selected test results for three loads: $150 \mathrm{~kW}, 200 \mathrm{~kW}$ and $250 \mathrm{~kW}$, which corresponds to the values of mean indicated pressure $\left(p_{i}\right)$ respectively: 8.3 bar, 10.1 bar, 12 bar and $50 \%, 60 \%$ and $75 \%$ of nominal load. 
Clogging (carbonization) the injector holes causes the rise of pressure in the injection system (Fig. 6.5). An increase in flow resistance results in a reduction of the injection pump delivery, followed by a reduction in the total fuel dose and therefore a decrease in cylinder power.

For every engine load specified in the tests, a decrease of $m_{\text {axi }}$ - maximum value intensity of heat release $\left(q z a k 1_{\max }<q w 1_{\max }\right)$ is characteristic by a dozen or so percent, a decrease of the mean indicated pressure (depending on the engine load from $5 \%$ to $12 \%$ ) and a decrease in the maximum value of combustion heat $Q_{\max }$ (Fig. 4-7). The $Q_{\max }$ drops are from several percent to over eleven percent and are comparable with the decrease in the mean indicated pressure $p_{i}$. For example, for an engine load of $50 \%$ (Fig. 5), the decrease in $p_{i}$ is $11.9 \%$ and $Q_{\max }$ is $11.2 \%$.

For all engine loads (Fig. 4-6) a decrease in $m_{\mathrm{axi}}$ and $Q_{\max }$ is observed. In the initial phase of the $Q$ rise (up to $190^{\circ} \mathrm{CA}$ ), the standard values and for the given damage do not differ, so the value of $p d_{1 Q}$ (Fig. 7) determined for the angle $\alpha_{p d 1 Q}$ equals zero.

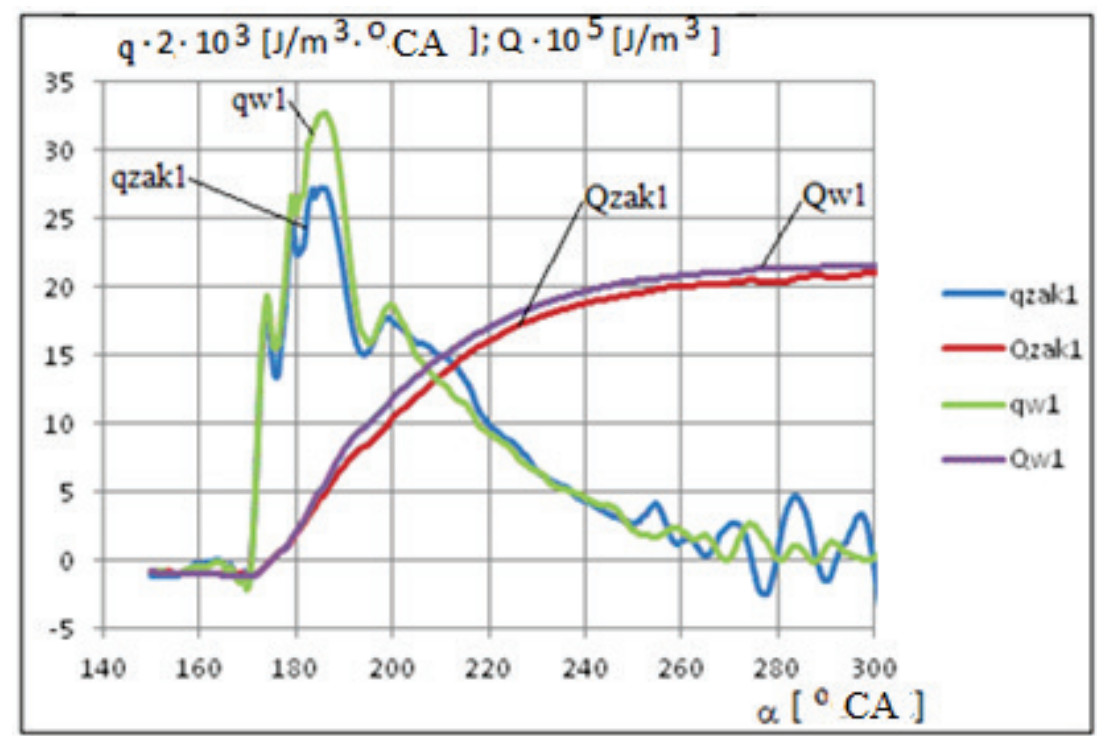

Fig. 4. Comparison of $q$ and $Q$ waveforms for the reference condition and clogged of the injector holes for a $75 \%$ load. Parameter values for the reference state: $p_{i}=12.0 \mathrm{bar}, m_{\text {axi }}=65.6 \cdot 10^{3} \mathrm{~J} /\left(\mathrm{m}^{3} \cdot{ }^{\circ} \mathrm{CA}\right), Q_{\max }=21.8 \cdot 10^{5} \mathrm{~J} / \mathrm{m}^{3}$. Parameter values after simulation of damage: $p_{i}=11.4 \mathrm{bar}, m_{a x i}=54.5 \cdot 10^{3} \mathrm{~J} /\left(\mathrm{m}^{3} \cdot{ }^{\circ} \mathrm{CA}\right), Q_{\max },=21.1 \cdot 10^{5} \mathrm{~J} / \mathrm{m}^{3}$

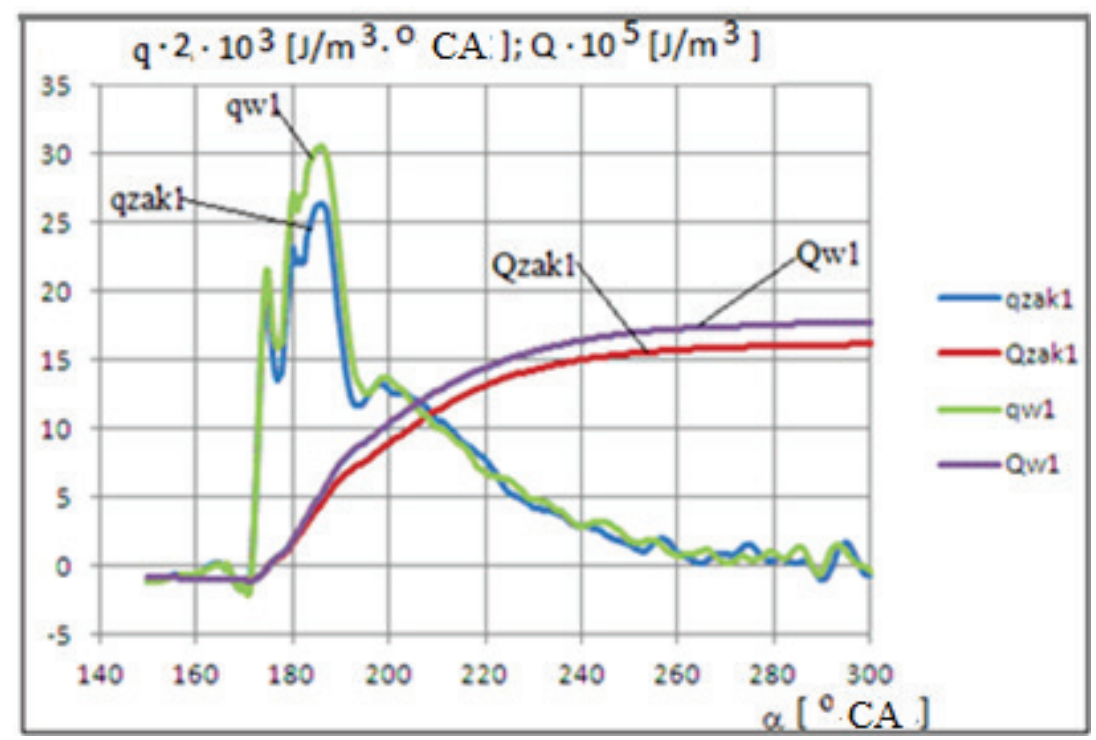

Fig. 5. Comparison of $q$ and $Q$ waveforms for the reference condition and clogged of the injector holes for a $60 \%$ load. Parameter values for the reference state: $p_{i}=10.1 \mathrm{bar}, m_{a x i}=61.2 \cdot 10^{3} \mathrm{~J} /\left(\mathrm{m}^{3} \cdot{ }^{\circ} \mathrm{CA}\right), Q_{\max }=18 \cdot 10^{5} \mathrm{~J} / \mathrm{m}^{3}$. Parameter values after simulation of damage: $p_{i}=9.09 \mathrm{bar}, m_{a x i},=52.9 \cdot 10^{3} \mathrm{~J} /\left(\mathrm{m}^{3} \cdot{ }^{\circ} \mathrm{CA}\right), Q_{\max },=16.2 \cdot 10^{5} \mathrm{~J} / \mathrm{m}^{3}$ 


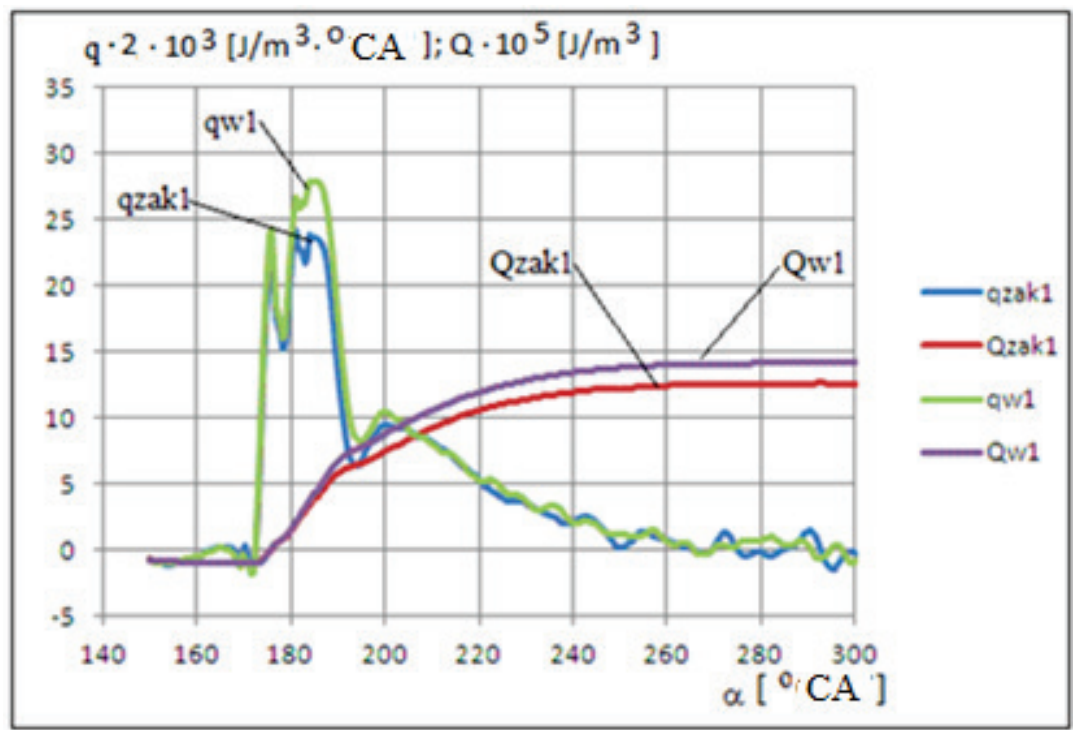

Fig. 6. Comparison of $q$ and $Q$ waveforms for the reference condition and clogged of the injector holes for a $50 \%$ load. Parameter values for the reference state: $p_{i}=8.27 \mathrm{bar}, m_{a x i}=55.8 \cdot 10^{3} \mathrm{~J} /\left(\mathrm{m}^{3}{ }^{\circ} \mathrm{CA}\right), Q_{\max }=14.3 \cdot 10^{5} \mathrm{~J} / \mathrm{m}^{3}$. Parameter values after simulation of damage: $p_{i}=7.29 \mathrm{bar}, m_{a x i}=48.4 \cdot 10^{3} \mathrm{~J} /\left(\mathrm{m}^{3} \cdot{ }^{\circ} \mathrm{CA}\right), Q_{\max },=12.7 \cdot 10^{5} \mathrm{~J} / \mathrm{m}^{3}$

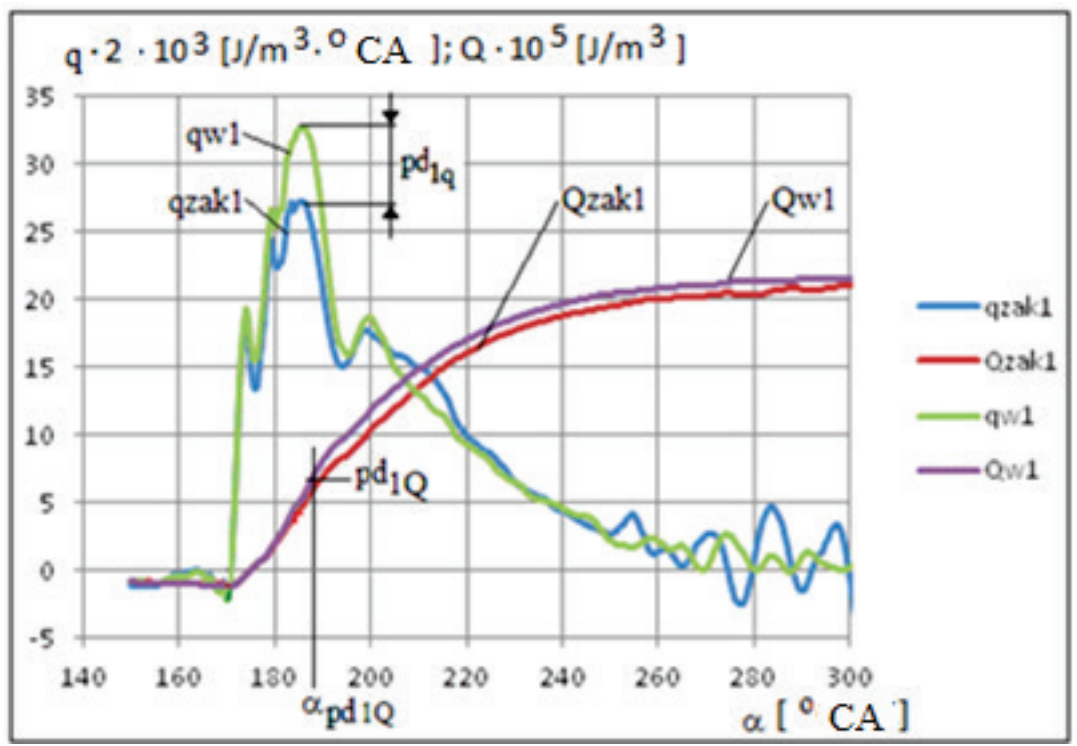

Fig. 7. Symptoms of clogged of the injector holes for 75\% load. Diagnostic parameters (symptoms): $p d_{1 q}>0, p d_{1 Q}=0$ for angle $\alpha_{p d I Q}$

For detection clogged of the injector holes, this symptom ( $p d_{1 Q}$ for $\alpha_{p d 1 Q}$ ) cannot be directly used. It should be noted that the simulation of the discussed damage was accomplished by blocking only 2 out of 9 injection holes, which was dictated by safety considerations (avoiding excessive pressure increase in the injection system).

By observing the changes in selected diagnostic parameters (Fig. 7), it should be noted that the level of parameter $p d_{1 Q}$ is slightly changed when $p d_{1 q}$ increases. The curves $q$ are identical in the range of values from the beginning of combustion to TDC $\left(180^{\circ} \mathrm{CA}\right)$.

\section{Conclusions}

The results show that, with a net heat release characteristics damage to the injection system can be detected. This allows you to opt out for the diagnostic use, the measurement and analysis of the pressure in the injection system. 
Course of heat release characteristics $q$ and $Q$ react primarily on the intensity of the fuel dosage to the cylinder and the value of the fuel dosage per cycle. holes.

The heat relation characteristics $q$ and $Q$ can be used in fault diagnostics - clogged the injector

For this purpose, the following diagnostic parameters have been distinguished:

$p d_{1 Q}$ - change of the maximum value of heat release intensity due to a given damage, in relation to the reference value,

$m_{\mathrm{axi}}-$ maximum value of intensity heat release for a given state,

$Q_{\max }$ - maximum value of net heat release for a given state.

\section{References}

[1] Jankowski, A., Heat transfer in combustion chamber of piston engines, Journal of KONES Vol. 17 No. 1, pp. 187-197, Warsaw 2010.

[2] Jankowski, A., Kowalski, M., Environmental Pollution Caused by a Direct Injection Engine, Journal of KONES, Vol. 22, No. 3, DOI: 10.5604/12314005.1168461, pp. 133-138, Warsaw 2015.

[3] Jankowski, A., Kowalski, M., Influence of the Quality of Fuel Atomization on the Emission of Exhaust Gases Toxic Components of Combustion Engines, Journal of KONBiN 4(36), DOI 10.1515/jok-2015-0055, pp. 43-50, Warsaw 2015.

[4] Jankowski, A., Laser Research of Fuel Atomization and Combustion Processes in the Aspect of Exhaust Gases Emission, Journal of KONES Powertrain and Transport, Vol. 15, No. 1 pp. 119-126, Warszawa 2008.

[5] Kowalski, M., Jankowski, A., Influence of the quality of fuel atomization on the emission of exhaust gases toxic components of combustion engines Journal of KONBIN, DOI 10.1515/jok-2015-0055, 36 (1), 43-50, 2015.

[6] Kowalski, M., Jankowski, A., Optymalizacja wtryskiwacza paliwa do silnika spalinowego z wykorzystaniem aparatury laserowej, Logistyka, Nr. 4, pp. 387-394, 2015.

[7] Kowalski, M., Jankowski, A., Research Performance of Novel Design of Diesel Engine, Journal of KONES, Vol. 24, Issue 4, DOI: 10.5604/01.3001.0010.3157, pp. 99-108, Warsaw 2017.

[8] Kowalski, M., Jankowski, A., Research Performance of Novel Design of Diesel Engine, Journal of KONES, Vol. 24, Issue 4, DOI: 10.5604/01.3001.0010.3157, pp. 99-108, Warsaw 2017.

[9] Kowalski, M., Jankowski, A., The use of laser equipment to optimize the operating parameters of the fuel injector of combustion engine, Journal of KONES, DOI: 10.5604/01.3001.0012.4792 Vol. 25, No. 4, pp. 199-206, Warsaw 2018.

[10] Piaseczny, L., Ocena niezawodności okrętowych silników spalinowych $w$ aspekcie tworzenia ich systemów diagnostycznych i obsługowych, Materiały Konferencji Naukowo-Technicznej, ITEO AMW, Gdynia 1992.

[11] Witkowski, K., Wykorzystanie analizy charakterystyk wydzielania ciepła do oceny stanu technicznego aparatury wtryskowej silnika okrętowego, Rozprawa $\mathrm{Nr} 490$, Wydawnictwo Politechniki Poznanskiej, Poznan 2013.

[12] Zurek, J., Kowalski, M., Jankowski, A., Modelling of Combustion Process of Liquid Fuels under Turbulent Conditions, Journal of KONES, Vol. 22, No. 4, DOI: 10.5604/12314005.1168562, pp. 355-344, Warsaw 2015.

Manuscript received 05 July 2019; approved for printing 22 September 2019 